\title{
AN IMPROVED THICK FILM ALUMINIUM CONDUCTOR PROCESS
}

\author{
R. E. COOPER, P. F. T. LINFORD and J. SAVAGE \\ Metallurgy Division, AWRE, Aldermaston, Berks UK†
}

(Received July 26, 1979)

\begin{abstract}
Aluminium thick film conductors offer very large cost advantages compared with noble metals and can also improve the reliability of circuits by eliminating gold-aluminium interfaces and their attendant intermetallic phenomena. To date however, it has not been possible to produce aluminium thick film conductors which are ultrasonically bondable to aluminium-silicon wire.

This paper describes a study of the microstructure and line profile of a commercially available aluminium thick film paste as a function of firing schedule. Scanning electron microscopy has revealed the mechanisms which control the sintering process and has suggested a revised firing schedule. It is shown that firing schedules exist which yield conductors with adequate ultrasonic bondability and conductivity. The results of bond ageing experiments on bond strength and conductivity are given for periods of up to $1200 \mathrm{~h}$ at temperatures of $60-200^{\circ} \mathrm{C}$.

It is shown that bonds of aluminium wire to aluminium thick film are resistant to loss of bond strength but suffer from loss of conductivity on ageing at $150^{\circ} \mathrm{C}$.
\end{abstract}

\section{INTRODUCTION}

Thick film conductor materials are most commonly based on gold, platinum, silver and binary alloys of such metals. These materials have good electrical conductivity, the necessary chemical stability to permit firing in air and, to varying extents, to resist degradation by the working environment during service. They have the disadvantage of high cost and because of this efforts have been made to develop thick film conductors using base metals such as copper and aluminium. In particular, an air fireable aluminium paste developed by Davy ${ }^{1}$ has been marketed for some years by Engelhard. This paste, when fired at $800-950^{\circ} \mathrm{C}$ yields conductors having a resistivity of $20 \mathrm{mohm} / \square$ i.e. comparable with palladium-silver or platinum-silver compositions. It has been found however that it is not possible to join aluminium wires to this conductor by using ultrasonic bonding and this acts as a severe constraint to the extensive use of the paste for hybrid circuits. The difficulty appears to be that the fired conductor is too soft to permit bonding, the aluminium wire instead being forced down through the conductor without any great pressure being developed at the wire-conductor interface. Accordingly a study has been carried out into the microstructure of the present commercially available paste in an effort to identify a means of increasing the hardness of the fired material. ${ }^{2}$

†Work supported by the Directorate of Components, Valves and Devices, UK Ministry of Defence, London.

\section{THE EFFECT OF FIRING TEMPERATURE ON CONDUCTOR CROSS-SECTION}

A series of samples was produced, each consisting of an array of tracks of aluminium conductor Engelhard T1486 on Alsimag 96\% alumina substrates, with two minute dwell times at firing temperatures in the range $400-850^{\circ} \mathrm{C}$.

Examination of the fired lines using a light section microscope showed that the major changes of the track cross-sectional dimensions occurred in the temperature interval $500-670^{\circ} \mathrm{C}$ and that the changes consisted of a small decrease in thickness from $500-625^{\circ} \mathrm{C}$ followed by a sudden increase in thickness, i.e. an expansion of the microstructure, for firing temperature above $625^{\circ} \mathrm{C}$ (see Figure 1(a)).

This behaviour may be contrasted with that of a frit bonded gold thick film conductor (Engelhard 9177) shown in Figure 1(b). In this case the thickness of the conductor decreases monotonically with increasing firing temperature, the maximum rate of densification occurring at a temperature at which the glass frit component softens.

The results shown in Figure 1(a) suggest that a structure obtained by firing below $650^{\circ} \mathrm{C}$ should be denser and therefore more suitable for ultrasonic wire bonding than that obtained by using the recommended firing temperature of $800-950^{\circ} \mathrm{C}$. The microstructural examinations which follow were therefore 


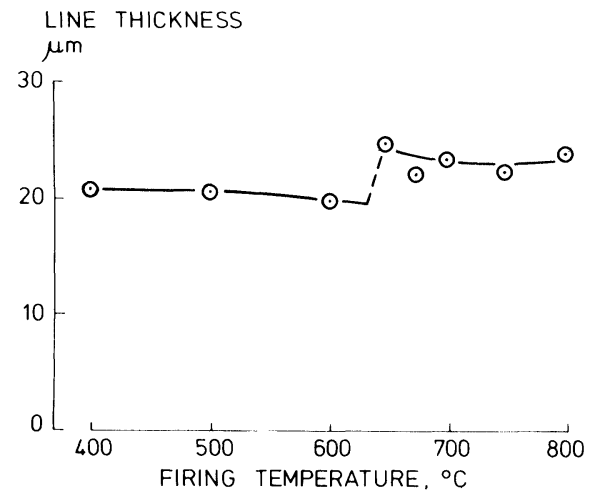

(a) Engelhard T1486 (aluminium)

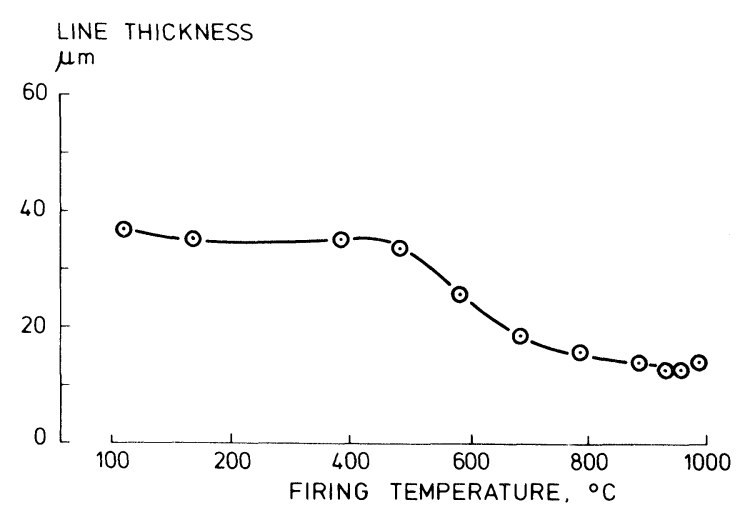

(b) Engelhard 9177 (gold)

FIGURE 1 The effect of firing temperature on line thickness for two thick film pastes.

confined to conductors fired in the temperature range $500-750^{\circ} \mathrm{C}$

\section{THE EFFECT OF FIRING SCHEDULE ON MICROSTRUCTURE}

Samples of the paste T1486 fired with two minute dwell times at temperatures between 500 and $750^{\circ} \mathrm{C}$ were examined using the scanning electron microscope. Figures 2(a)-2(h) show typical microstructures. The small lighter coloured particles are the frit component and the larger particles are the aluminium phase.

Examination showed that sintering of the aluminium phase occurred for firing temperatures of $625^{\circ} \mathrm{C}$ or more. At temperatures of $675^{\circ} \mathrm{C}$ (i.e. above the melting point of aluminium) a different process occurs which results in expansion of the micro- structure. At these temperatures wherever two aluminium particles (or drops, since they are liquid) are in contact, due to the sintering process which has occurred as the temperature was raised, the higher surface-tension-induced pressure in the smaller drop leads to its contents being injected into the larger drop. Thus preferential growth of larger aluminium particles is observed and this process disrupts the packing of the metal particles and gives a less dense microstructure. Since the firing process is carried out in air all the aluminium particles carry a considerable oxide coating and the loss of the metal contents of the smaller particles leaves flattened oxide shells attached to the large metal particles - see Figure 2(f) for example. These microstructural observations therefore explain the effect of firing temperature on conductor cross section shown in Figure 1(a).

The effect of dwell time at $625^{\circ} \mathrm{C}$ and at $640^{\circ} \mathrm{C}$ on microstructure was determined but was found not to be very large. A variation of dwell time from two to eight minutes had little effect on microstructure although that obtained after thirty or sixty minutes was appreciably more sintered in appearance.

\section{THE EFFECT OF FIRING SCHEDULE ON ELECTRICAL RESISTIVITY}

Electrical resistivity measurements were made using a four probe system and the results are shown in Figures 3 and 4 . Figure 3 shows the effects of peak firing temperature and dwell time on electrical resistivity. Values of $50-70 \mathrm{mohm} / \square$ are obtainable under firing conditions which yield a dense microstructure. Lower resistivities are attainable but only under conditions which give the more porous microstructure. Resistivities of $50-70 \mathrm{mohm} / \square$, whilst considerably higher than those exhibited by pure noble metal thick film conductors, are comparable with those of alloys such as platinum-gold and palladium-gold and are quite usable. Figure 4 shows the resistivity as a function of peak firing temperature (two minute dwell time) over a wide range of temperatures. The general form of the curve is interesting, showing a general tendency for a decrease in resistivity with increasing firing temperature but superimposed on this an increased resistivity in the range $660-750^{\circ} \mathrm{C}$. The former trend is probably due to the increased amount of diffusion (either solid or liquid phase) with increasing firing temperature. The latter effect is presumably due to the disruption of the microstructure mentioned in Section 3. 


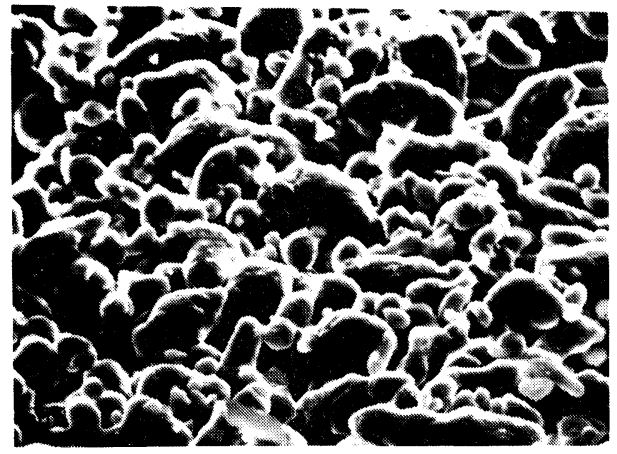

(a) $500^{\circ} \mathrm{C}$

$10 \mu \mathrm{m}$

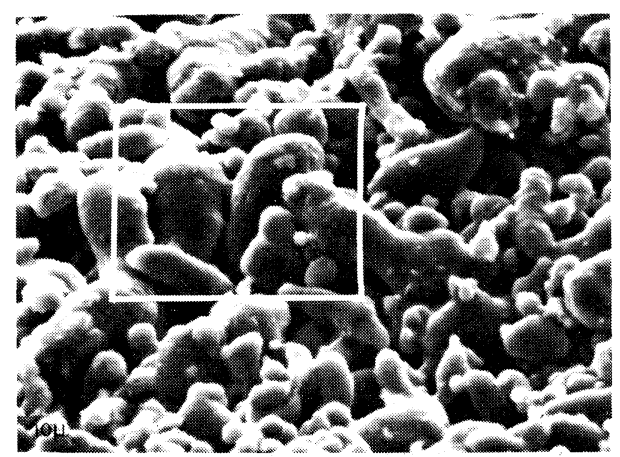

(c) $625^{\circ} \mathrm{C}$

$10 \mu \mathrm{m}$

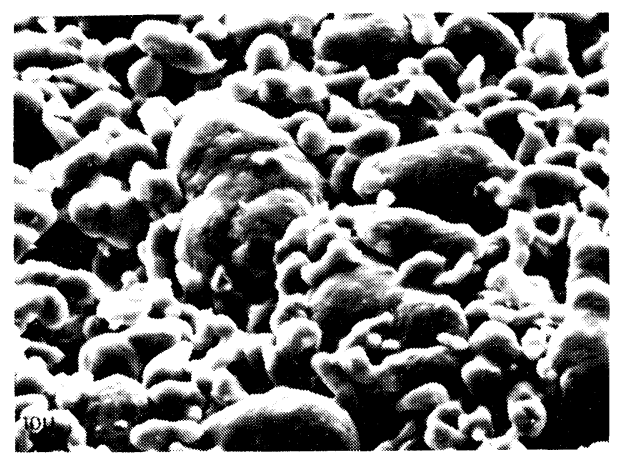

(e) $675^{\circ} \mathrm{C}$

$10 \mu \mathrm{m}$

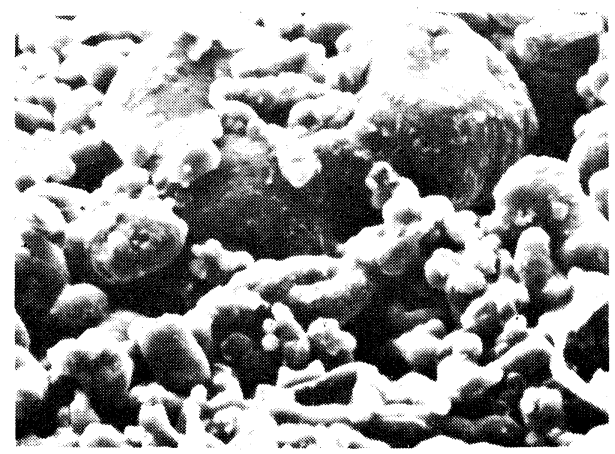

(g) $750^{\circ} \mathrm{C}$
$10 \mu \mathrm{m}$

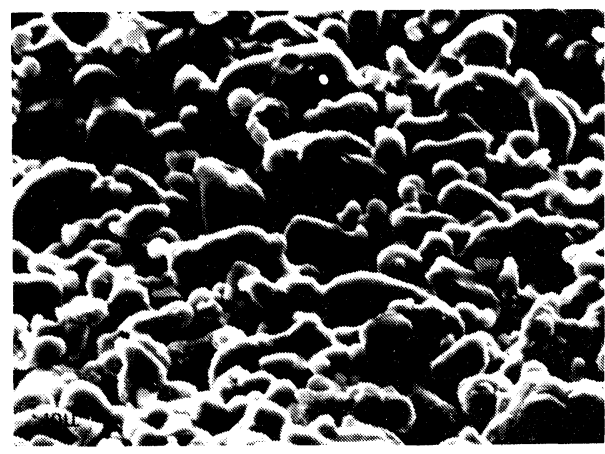

(b) $600^{\circ} \mathrm{C}$

$10 \mu \mathrm{m}$

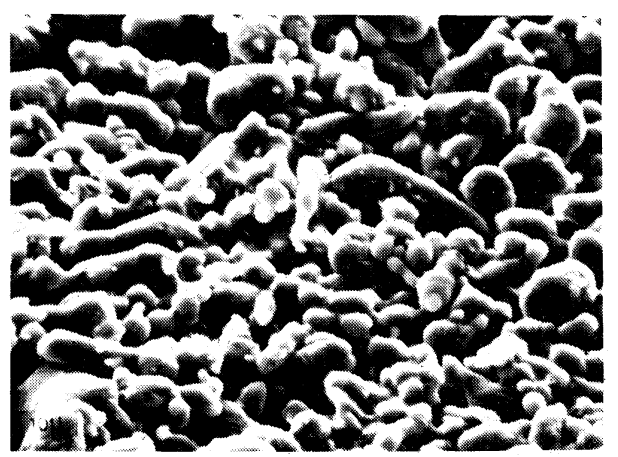

(d) $650^{\circ} \mathrm{C}$

$10 \mu \mathrm{m}$

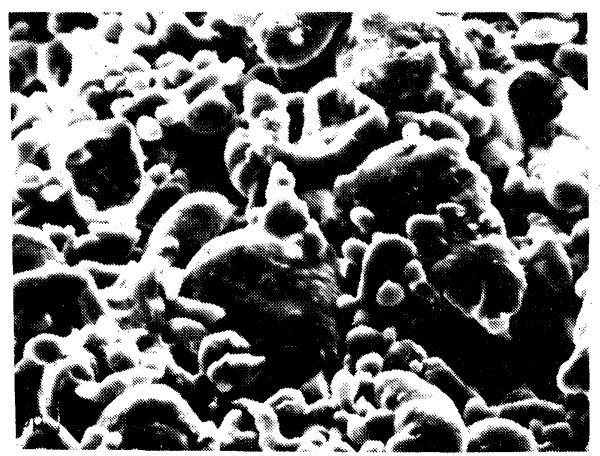

(f) $700^{\circ} \mathrm{C}$

$10 \mu \mathrm{m}$

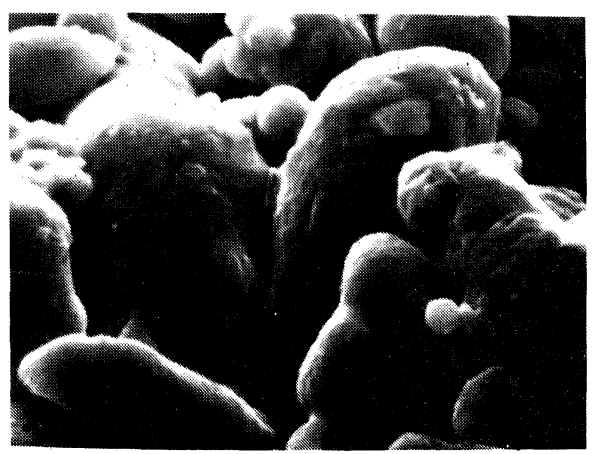

(h) $625^{\circ} \mathrm{C} \quad 10 \mu \mathrm{mL}$

FIGURE 2 Scanning electron micrographs of T1486 aluminium paste fired at different temperatures. 


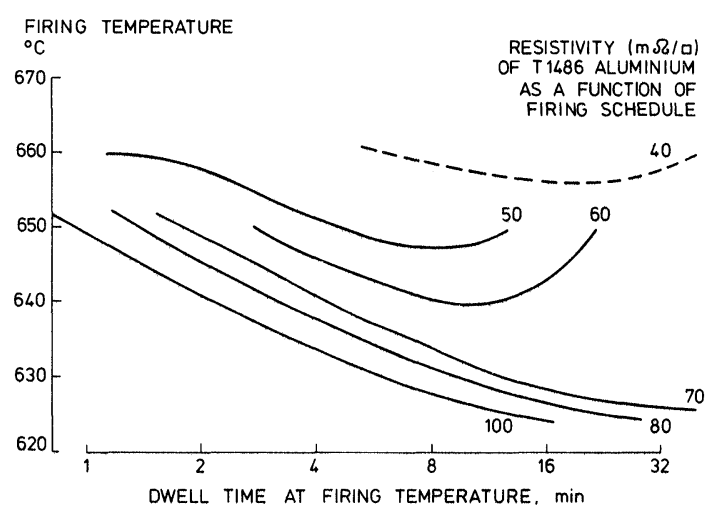

FIGURE 3 The effect of firing schedule on resistivity of T1486 aluminium paste.

\section{THE EFFECT OF FIRING SCHEDULE ON ULTRASONIC BONDABILITY}

A series of specimens of T1486 aluminium was made with firing temperature of 10 minutes. Ultrasonic wedge bonded wire loops were made using a Kulicke and Soffa model 484 bonder with Kerry model KS 501 power unit and Gaiser type 2013-25 bonding wedge. The wire was Secon $25 \mu \mathrm{m}$ aluminium $1 \%$ silicon ( $2 \frac{1}{2} \%$ elongation condition).

It was found that the optimum settings of time, tool movement amplitude and clamping force were the same for specimens fired between 600 and $740^{\circ} \mathrm{C}$ but that increased amplitude of tool movement was necessary for optimum bonding onto specimens fired at $760^{\circ} \mathrm{C}$ or above.

Bond strengths were measured by vertical pulling at the centre point of each loop. Thirty tests were carried out per firing condition and the results are given in Figures 5 and 6. Figure 5 shows the effect of firing temperature on the percentage yield of good loops, a good loop being defined as one where both bonds have strengths greater than $2 \mathrm{~g}$. It can be seen that the yield generally decreases with increasing firing temperature although there is a rapid change near the melting point of aluminium. Generally speaking the firing temperature range which gives an acceptable yield of bonds is $600-660^{\circ} \mathrm{C}$ and Figure 6 shows the distribution of bond strengths for firing temperatures in this range. It can be seen that the usual bond strength is $4-5 \mathrm{~g}$ and this has also been found to be the case for bonds onto higher firing temperature films (not illustrated). The failure mode for temperatures up to $760^{\circ} \mathrm{C}$ was generally lifting of the whole bond and above that temperature it was heel breakage due to excessive thinning of the wire during bonding.

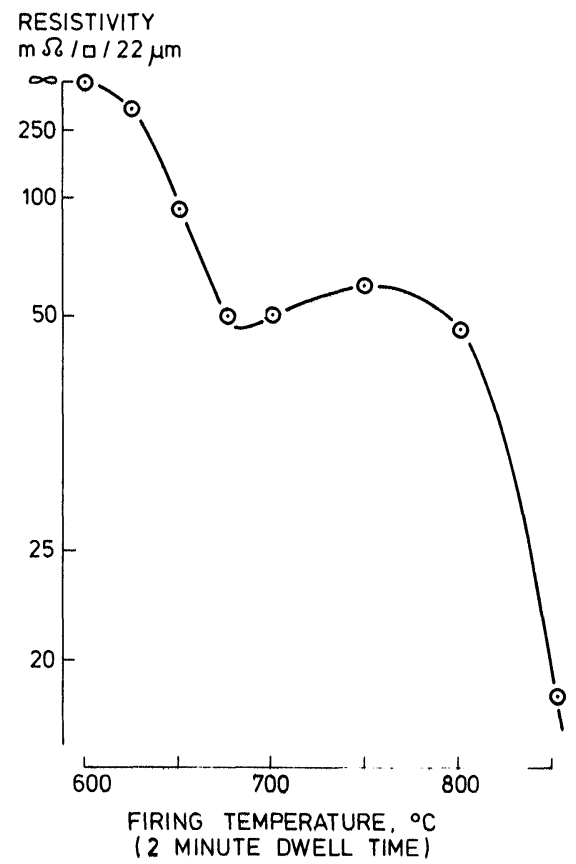

FIGURE 4 The effect of firing temperature on resistivity of T1486 aluminium paste over a wide temperature range.

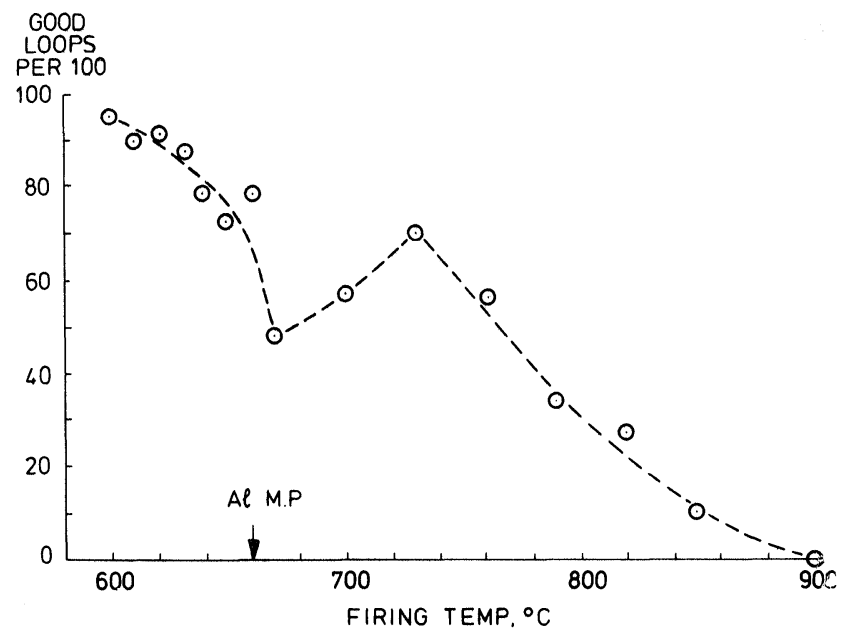

FIGURE 5 Variation of bondability of T1486 aluminium paste with firing temperature (10 minute dwell time).

\section{EFFECTS OF AGEING ON BOND STRENGTH AND ON BOND AND CONDUCTOR CONDUCTIVITY}

A programme of work on ageing effects of aluminium $1 \%$ silicon wire bonds to T1486 aluminium and to 

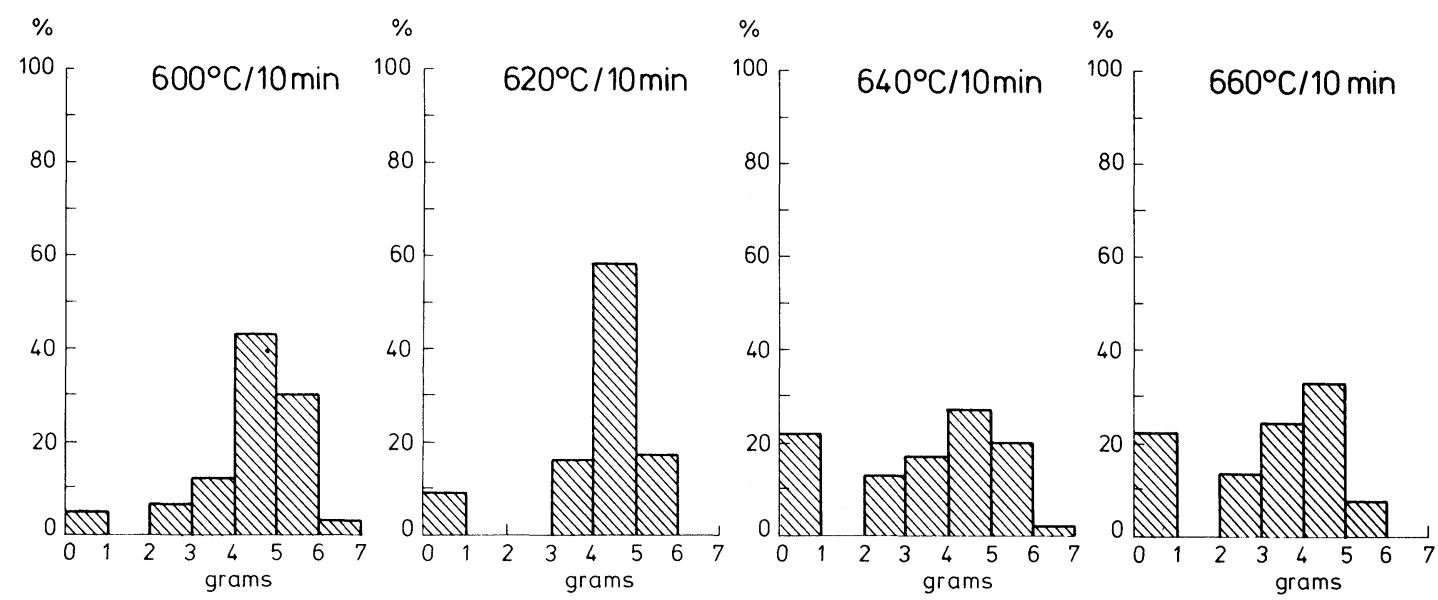

FIGURE 6 Bond strength for firing temperatures from $600^{\circ} \mathrm{C}$ to $660^{\circ} \mathrm{C} 25 \mu \mathrm{m} \mathrm{Al} / 1 \%$ Si wire bonded to T1486 aluminium paste.

T4474 gold is currently being carried out and a selection of the data obtained so far is presented in Figures 7-10. Ageing temperatures covered are RT, $60,100,150$ and $200^{\circ} \mathrm{C}$ and times up to $1200 \mathrm{~h}$ have been attained.

Figure 8 shows the effect of ageing for T1486 fired at 600,610 and $620^{\circ} \mathrm{C}$ and for T4474 (fired at $850^{\circ} \mathrm{C}$ ). It can be seen that the $\mathrm{T} 1486$ aluminium paste compares favourably with the gold in terms of retention of bond strength. The initial decline in bond strength is due to annealing of the heel of the wire bond as can be seen from Figure 7 which shows the location of the failure. The other fluctuations in bond strength on ageing are not at present explicable but it is noticeable that these fluctuations are greater for T1486 fired at the higher temperature and for the lower temperature ageing experiments.

Figure 9 shows the conductance of the total wire loop (i.e. wire loop plus two bonds plus a small amount of conductor pad associated with each bond) for T1486 and for T4474 whilst Figure 10 shows the line conductivity for a printed strip of T1486 and for T4474. It can be seen that ageing affects the conductivity of T1486 to a considerable extent, almost halving the conductivity.

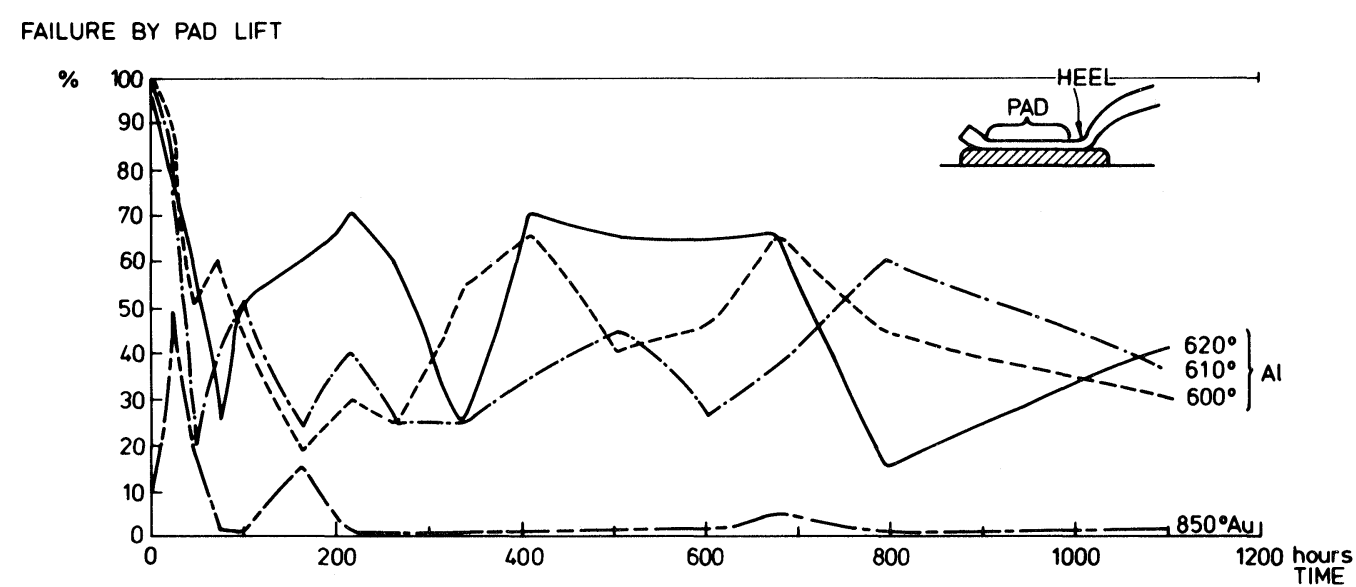

FIGURE 7 Effect of thermal soak at $150^{\circ}$ on the failure mode of 25 micron Al/Si wire bonds to Engelhard T1486 fired at $600^{\circ} \mathrm{C}, 610^{\circ} \mathrm{C}$ and $620^{\circ} \mathrm{C}$ and to gold fired at $850^{\circ} \mathrm{C}$. 
INITIAL BOND STRENGTH (IBS)

$\% \quad 110$

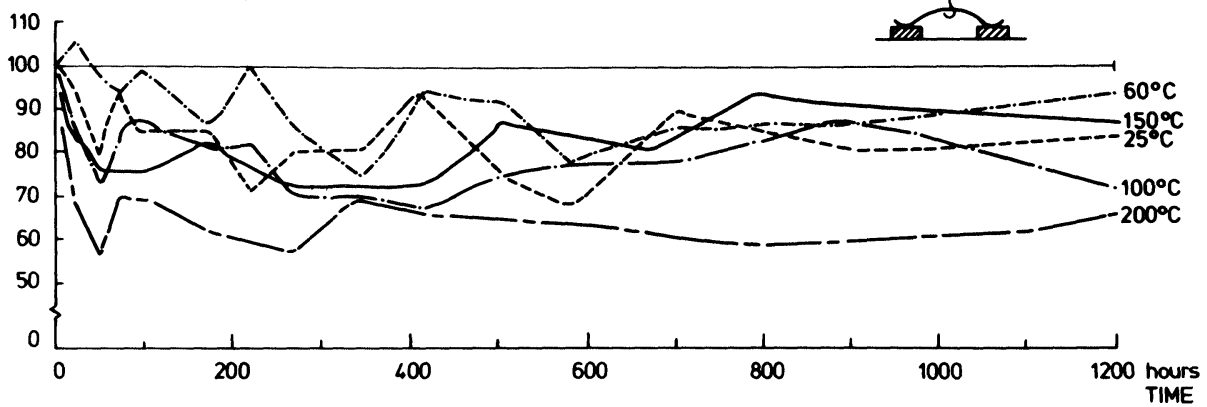

(a) Engelhard T1486 fired at $6.00^{\circ} \mathrm{C}$-mean IBS 4.02 grams

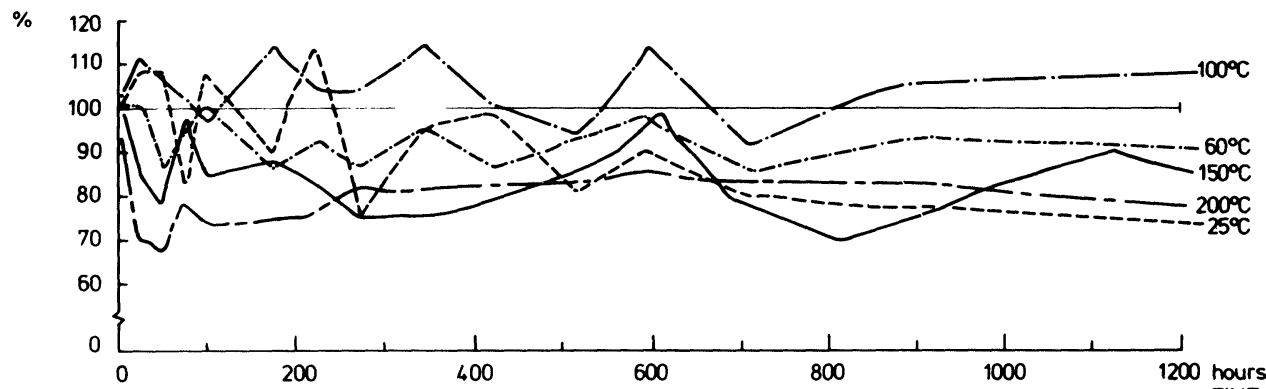

(b) Engelhard T1486 fired at $610^{\circ} \mathrm{C}$-mean IBS 3.38 grams

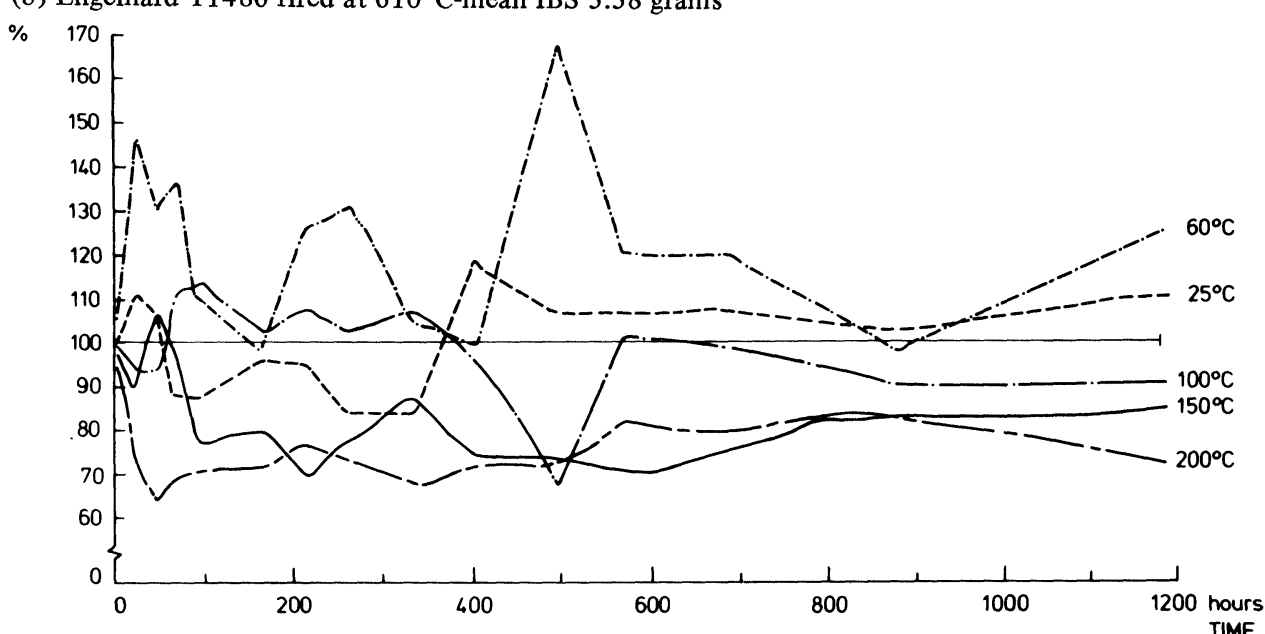

(c) Engelhard T1486 fired at $620^{\circ} \mathrm{C}$-mean IBS 2.94 grams

TIME

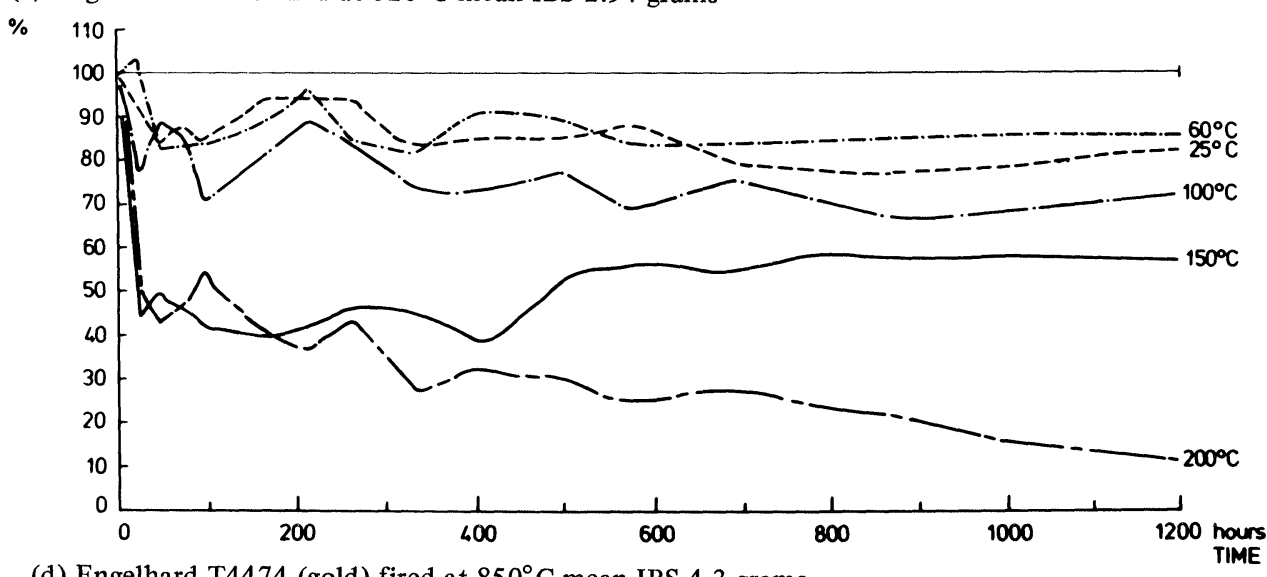

(d) Engelhard T4474 (gold) fired at $850^{\circ} \mathrm{C}$-mean IBS 4.3 grams

FIGURE 8 Effect of thermal soak on the strength of 25 micron $\mathrm{Al} / \mathrm{Si}$ wire bonds. 


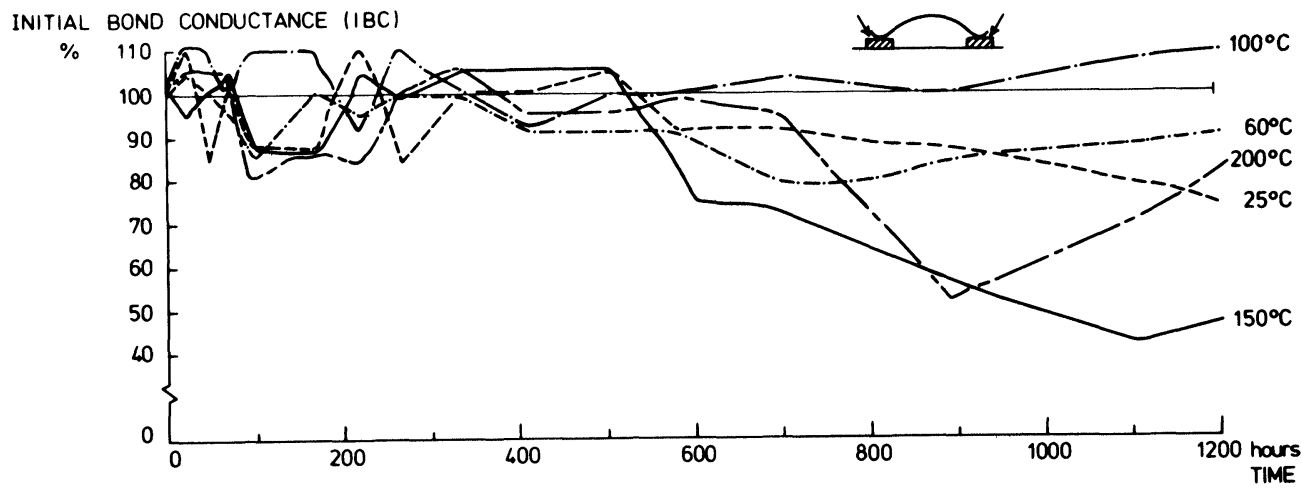

(a) Engelhard T1486 fired at $600^{\circ} \mathrm{C}$-mean IBC 9.26 mho

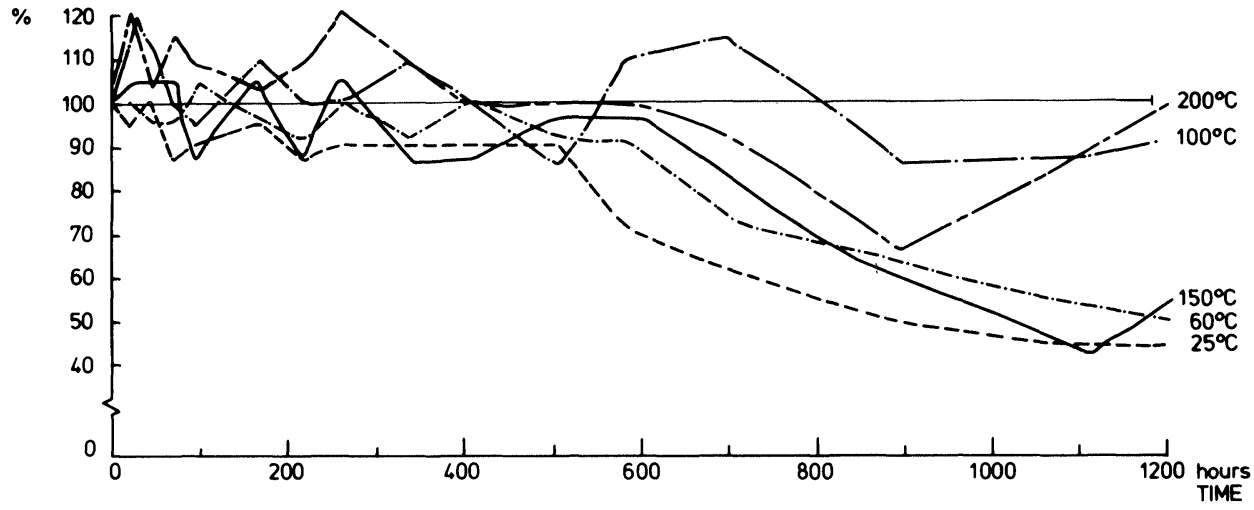

(b) Engelhard T1486 fired at $610^{\circ} \mathrm{C}$-mean IBC 9.01 mho

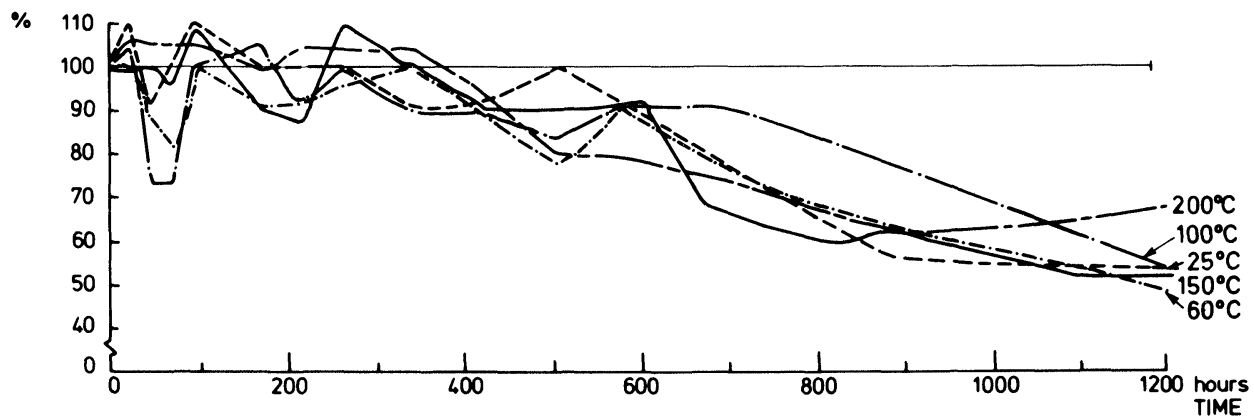

(c) Engelhard T1486 fired at $620^{\circ} \mathrm{C}$-mean IBC 9.17 mho

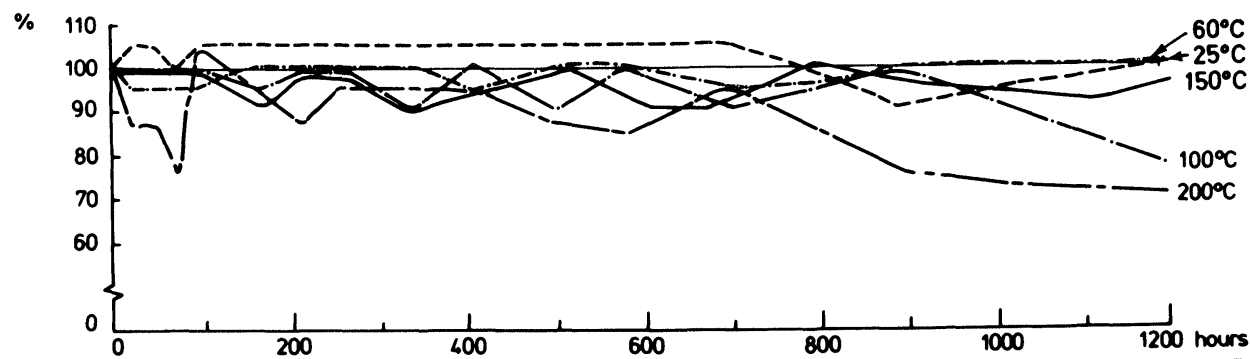

(d) Engelhard T4474 (gold) fired at $850^{\circ} \mathrm{C}$-mean IBC $9.8 \mathrm{mho}$

FIGURE 9 Effect of thermal soak on the conductance of 25 micron $\mathrm{Al} / \mathrm{Si}$ wire bonds. 
INITIAL CONOUCTIVITY (IC)

$\%$

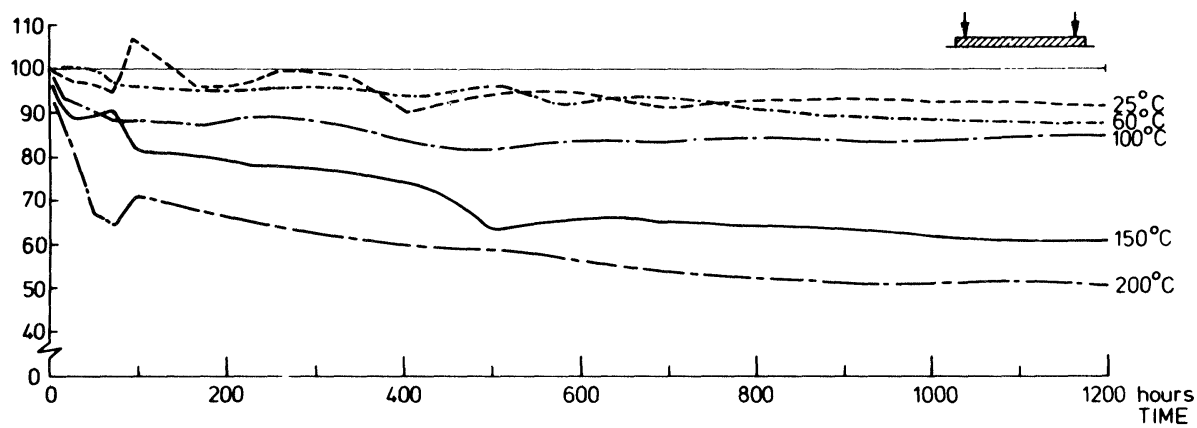

(a) Engelhard T1486 fired at $600^{\circ} \mathrm{C}$-mean IC 2.5 mho sq

$\%$

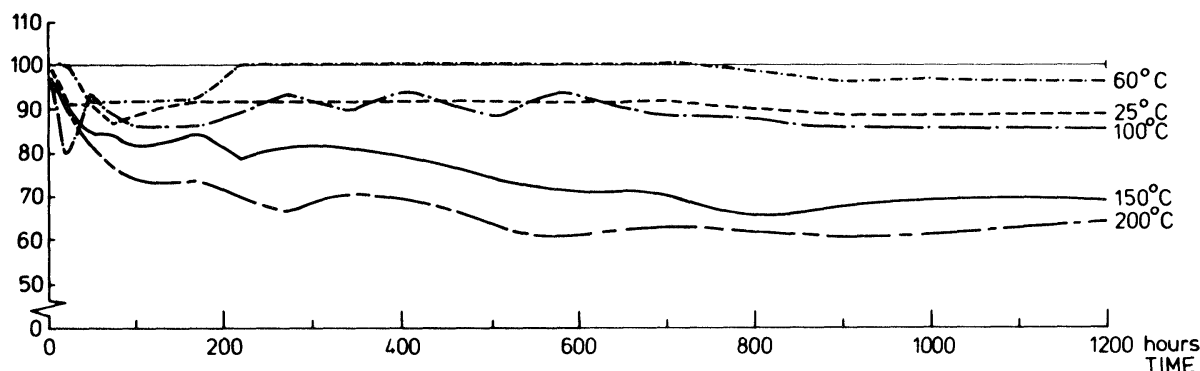

(b) Engelhard T1486 fired at $610^{\circ} \mathrm{C}$-mean IC 8.47 mho sq

$\%$

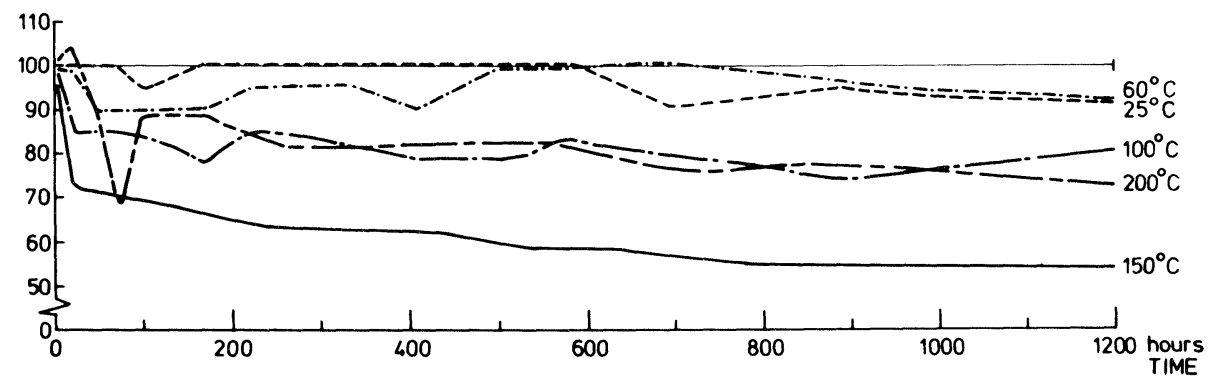

(c) Engelhard T1486 fired at $620^{\circ} \mathrm{C}$-mean IC 11.1 mho sq

$\%$

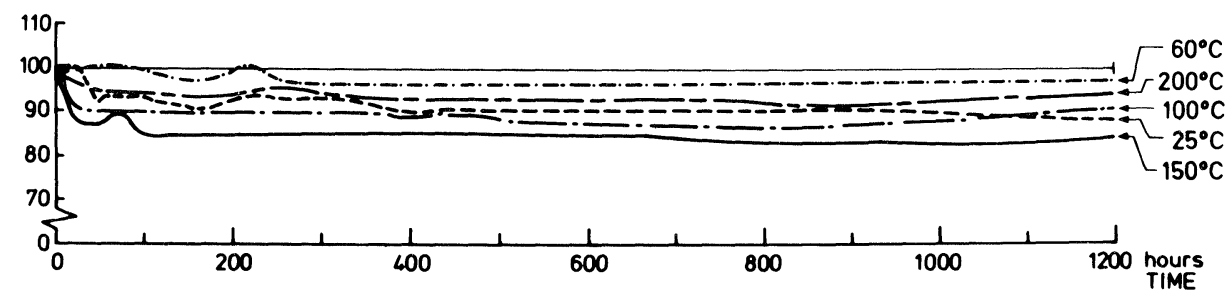

(d) Engelhard T4474 (gold) fired at $850^{\circ} \mathrm{C}$-mean IC $357.1 \mathrm{mho}$ sq

FIGURE 10 Effect of thermal soak on conductivity. 


\section{DISCUSSION AND CONCLUSIONS}

It has been found that the existing commercially available aluminium thick film paste T1486 may be fired at temperatures well below the recommended $800-950^{\circ} \mathrm{C}$. The lower the firing temperature the higher is the resistivity but the greater the ultrasonic bondability. The temperature range of most interest is $600-660^{\circ} \mathrm{C}$. For $600^{\circ} \mathrm{C}$ firing a bonded loop yield of $95 \%$ is obtained but the material is barely conducting, whilst for $660^{\circ} \mathrm{C}$ firing a loop yield of $75 \%$ is attained together with a resistivity of $40 \mathrm{mohm} / \square$. (Ten minute dwell times in all cases.)

Ageing for periods up to 1200 hours at $150^{\circ} \mathrm{C}$ causes a slight reduction in bond strength but a much larger decrease in bond and conductor conductivity. The latter effect combined with the already rather low conductivity of bondable T1486 suggests that a double printing method may be necessary for circuits which incorporate wire bonds. Such a method would involve printing and firing the conductor array at $800-950^{\circ} \mathrm{C}$ and then adding the bonding pads and firing them at $600-620^{\circ} \mathrm{C}$.

This work will be continued to a total ageing time of $\sim 2000$ hours and will be reported more fully at a future date.

\section{ACKNOWLEDGEMENT}

The authors would like to thank Mr R. H. Bauckham of Bradford University who carried out the ageing programme whilst attached to their laboratories for industrial experience.

\section{REFERENCES}

1. N. Davy, Aluminium Metallising Paste British Patent No. 1378520 (1971).

2. J. Savage, Patent of Addition to British Patent No. 1378520 (May 1978).

Copyright $\odot$ Controller, HMSO, London, 1979 

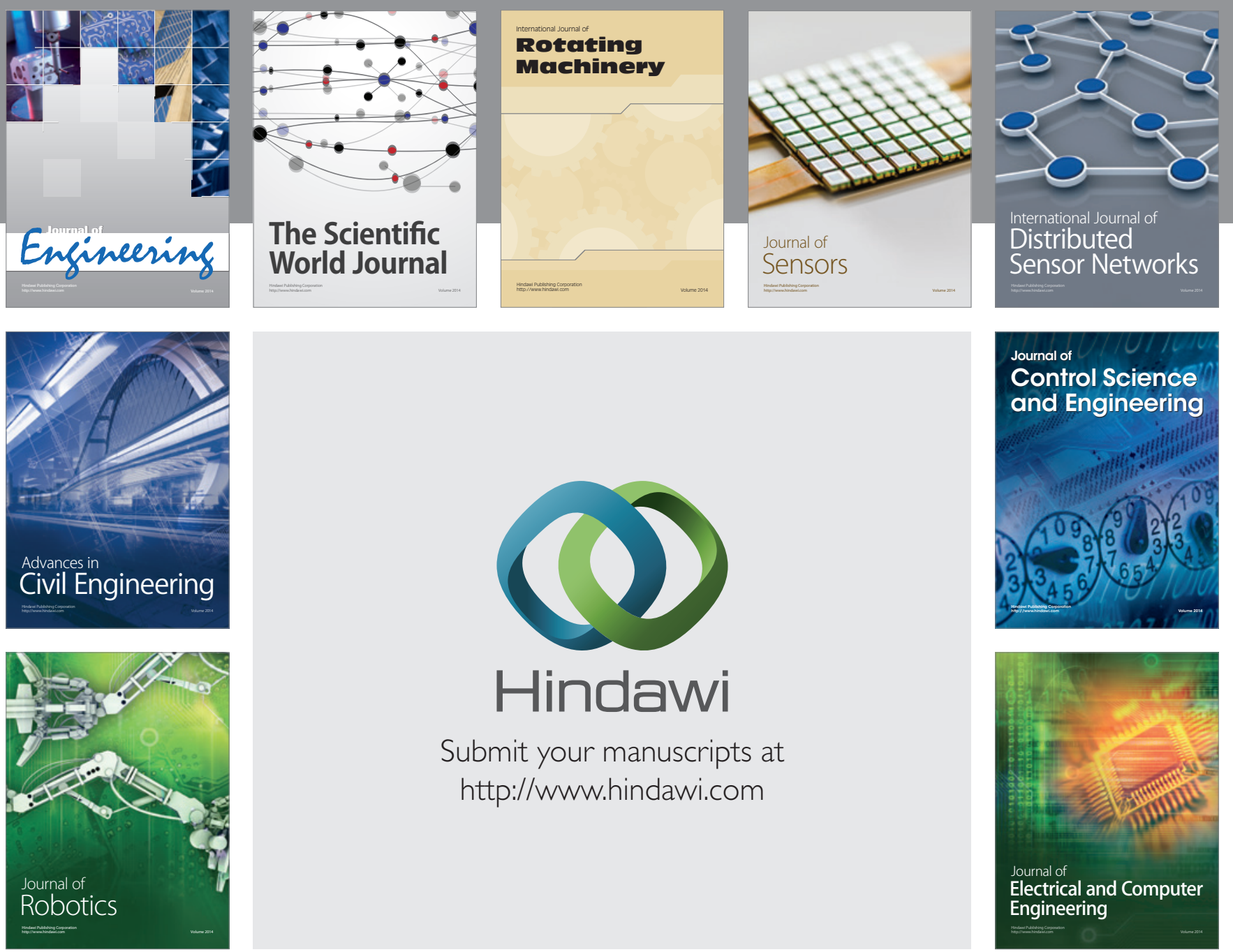

Submit your manuscripts at

http://www.hindawi.com
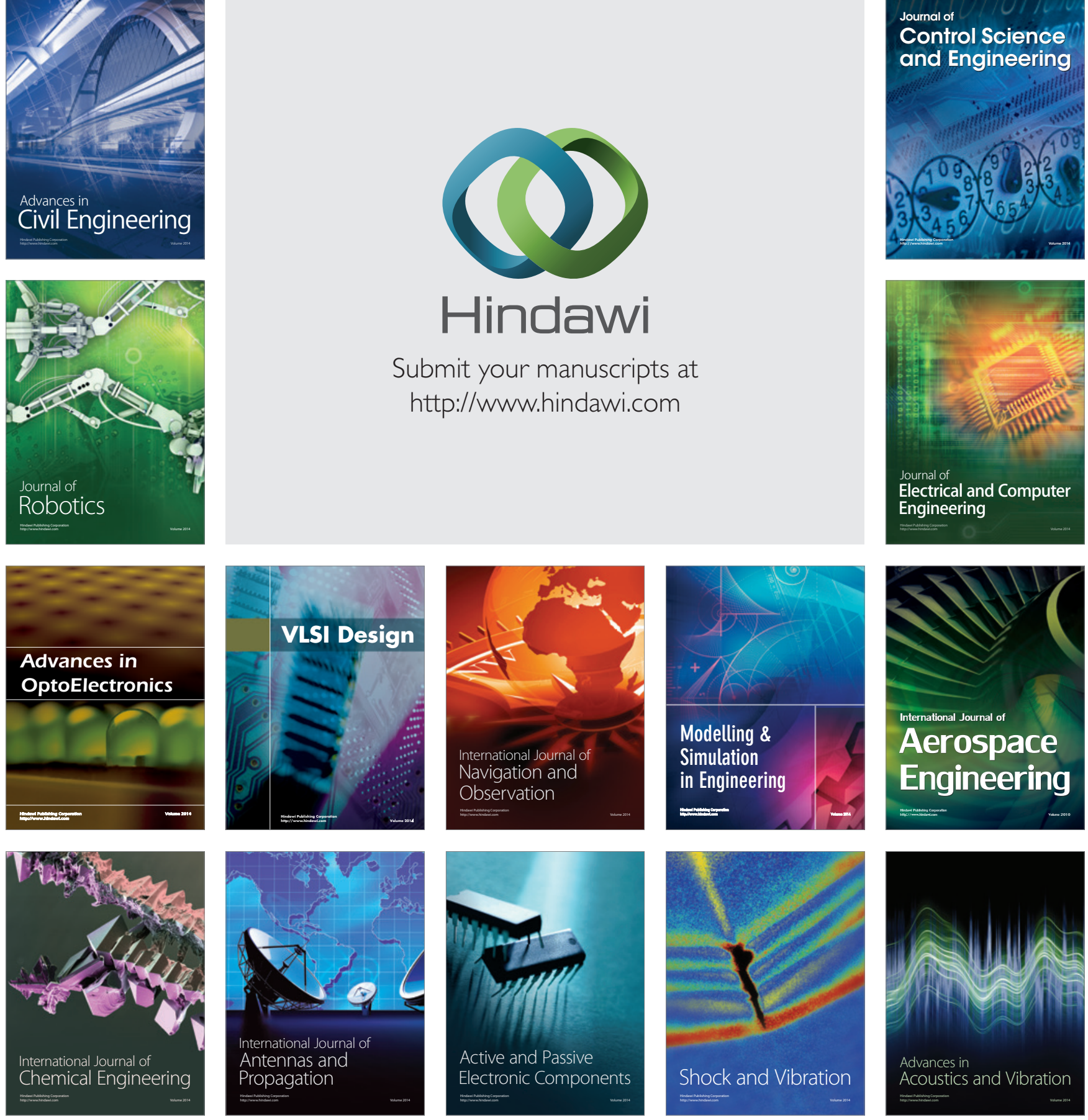